\title{
Effect of electric power interchanges using a smart grid: in terms of city characteristics
}

\author{
Y. Nakagawa, J. Ochiai \& M. Taniguchi \\ Graduate School of Systems and Information Engineering, \\ University of Tsukuba, Japan
}

\begin{abstract}
In recent years, tests and investigations aimed at the realization of a sustainable city by smart grids using renewable energy have been ongoing worldwide. However, those field tests do not take into consideration the fact that the city characteristics include the manner of using electric vehicles. This important smart grid component strongly influences city characteristics. In fact, the degree of that effect expected for cities of each kind has not been reported. Therefore, this study analyzes the difference of effects of local electricity production for local consumption using photovoltaic resources, with introduction of smart grids in Japanese cities. The analyses specifically address electric power supply and demand for houses, which account for most building areas in cities. The daily electricity supply and demand circumstances were estimated hourly based on traffic data and solar radiation data nationwide. Moreover, based on the calculated results, we created a multiple regression model using data of city characteristics such as the car ownership rate and housing complexes, and applied it in all cities of the Tokyo metropolitan area. We then analyzed the relation between the effect of local electricity production for local consumption and the city characteristics. Results of those analyses demonstrate that cities with a higher effect of the local electricity production for local consumption have characteristics such as trends in nuclear families, a high ratio of a car ownership, and newly built detached homes. Furthermore, the effect is greater in suburban areas than in urban areas of metropolitan Tokyo. Although the distance from the urban area extends far into the suburban area, this effect decreases with distance. Keywords: smart grid, local electricity production for local consumption, city character, electric vehicle, multiple regression model.
\end{abstract}




\section{Introduction}

In recent years, introduction of smart grids is accelerating worldwide. The backgrounds vary among countries, as do strategies of coping with decrepit electricity transmission grids, acceleration of demographic aging, and concentration of population in large cities. However, a common objective of these smart city concepts is the extension of renewable energy, along with use of a smart grid, to cope with increasingly severe environmental problems.

In this age of large-scale introduction of renewable energy, important difficulties have arisen. Particularly, strong weather-dependence of solar and wind power generation puts a heavier load on the power grid system. Moreover, a reverse power flow problem arises because of the flow of large amounts of surplus power generated in homes and businesses to the power grid. Regarding these matters, Lund and Kempton [1] and Kang and Recker [2] described that electric vehicles $(\mathrm{EV})$ with a storage function are valuable components of the smart grid. Moreover, regarding dynamic pricing, Brand [3], Alexander [4], and other researchers have examined residences and businesses in relation to effects of smart grids. Nevertheless, the effects which can be expected for cities of different kinds when such technologies are introduced into existing cities remain unknown. Particularly, no study has specifically addressed the travel behaviour of residents including the use of $\mathrm{EV}$, which is the important component of the smart grid. Additionally, no study has particularly addressed city characteristics that affect the overall amounts of photovoltaic (PV) and electricity consumption (EC). In fact, introduction of plans related to the above city characteristics is important to achieve efficient introduction of the smart grid.

From the above, we define the smart grid as a technique of planning electric power interchange between the residences in municipalities consisted of residential PV and EV. In this study analyzes the degree of local electricity production for local consumption by introduction of smart grids in all of 1750 municipalities in 2010 in Japan. The analyses specifically address travel behaviour in all municipalities and electric power supply and demand of houses, which account for most building areas in the cities. Finally, the purpose of this study is to contribute to the efficient future widespread use of smart grid and renewable energy.

\section{Contents and advantages of this study}

The study contents were shown as following. This paper calculated the daily electricity supply and demand situation among hourly by municipalities unit using the amount of PV and residential EC. Moreover, we established adoption rate of EV and understand the daily manner of using EV. Furthermore we estimate the usable amount of storage by EV for a surplus electric power of the $\mathrm{PV}$ in resident municipalities.

Based on the calculated result, we analyzed what kinds of municipalities have what kind of possibility of local electricity production on local consumption. Local electricity production on local consumption means that the municipalities 
can provide electricity power to residential EC by residential PV from electric power interchanges by smart grid.

Based on the above contents, this study has advantages as shown below.

1) This study is the first to calculate the effect of local electricity production on local consumption using a smart grid. It is based on city characteristics and the manner of using EV as batteries in all municipalities in Japan.

2) Traffic data that cover all Japanese municipalities satisfy authenticity by investigation of reliability testing.

3) Statistical analysis reveals the factors affecting the degree of local electricity production on local consumption.

\section{Main data and the multiple regression model}

\subsection{Outline of the used data}

This study requires understanding of the daily behaviour of residents. Therefore, we used the Road Traffic Census owner interview OD Surveys 2005 (RTCS). In fact, RTCSs have been conducted nationwide for the past 3-5 years by the Ministry of Land, Infrastructure, Transport and Tourism. The survey items include the following: The manner of using cars such as the departure place, time, travel distance, and car ownership in the household unit. Based on these data, we estimated the adoption rate of EV and understood EV travel behaviour for a day. However, not all municipalities have a sufficient number of samples. Therefore, the selection of a date used for population rate test reference the Yonezawa and Matsuhashi [5] which determined the statistical reliability of the number of samples per municipality. Regarding data of small towns and villages, we use those compiled per county. Therefore, we use 701 municipalities' data satisfying the reliability to be analysed nationwide from all 1186 municipalities. In addition, to calculate the amount of PV and residential EC based on the national census taken in 2010, statistical surveys on housing and land taken in 2008 by the Ministry of Internal Affairs and Communications and 837 locations nationwide database of solar radiation data on 1990-2009 by New Energy and Industrial Technology Development Organization (NEDO).

\subsection{Object area of a multiple regression model}

First, this study analyzes the effects of local electricity production for local consumption targeted the municipalities. Next based on the calculated result of its potentials, we create a multiple regression model using data of city characteristics such as the car ownership rate, and housing complexes. Then we applied it in all cities in the Tokyo metropolitan area, as depicted in Fig. 1. We show a relation between the effect of local electricity production for local consumption and city characteristics.

Tokyo metropolitan area: This area consists of Ibaraki, Tochigi, Gunma, Saitama, Chiba, and Kanagawa prefectures centring around Tokyo, the national capital. The area's population is 42 million people, which accounts for about 


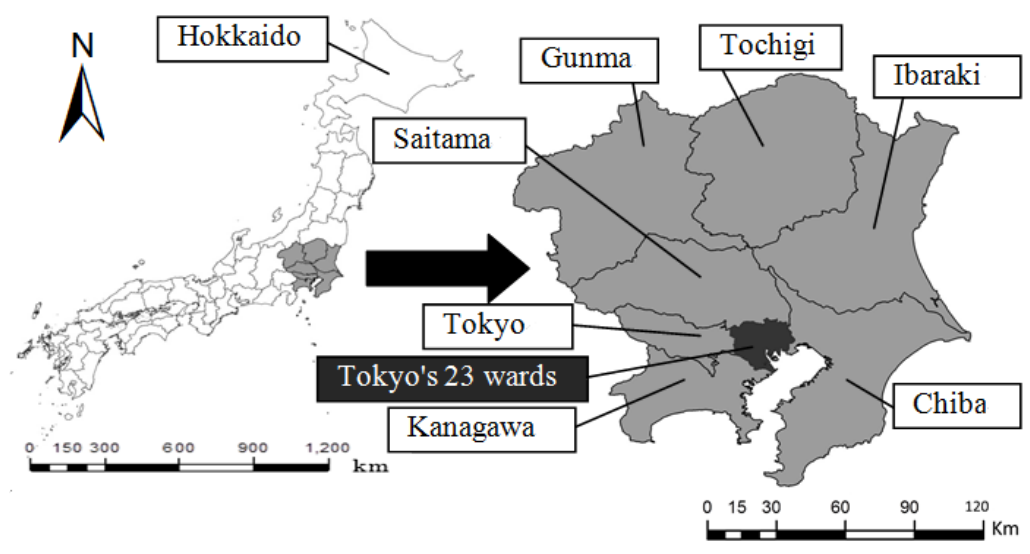

Figure 1: $\quad$ Tokyo metropolitan area.

one-third of the population of Japan. It includes many cities with various characteristics from metropolitan to suburban municipalities.

\section{Indication of local electricity production for local consumption}

\subsection{Method of PV estimation}

Estimation of the amount of PV is carried out in the following steps through reference to a survey of the Resources and Energy Agency [7]. 1) To estimate the installation available area of the solar panels per house of each detached home and apartment building, considering the sunny side and maintenance equipment. 2) In Japan, the installation of solar panels must satisfy quakeresistance standards that have been applied since 1980. Therefore, we calculate the installation area of solar panels by every municipality; incorporate consideration of the building ratio that satisfies the quake-resistance standards. 3) We create a residential ratio among hours of daylight using data of hours of sunlight to the roof and number of residence by every municipality. 4) Based on this ratio data and dividing the available installation area of the solar panels in necessary area per unit $\left(11.55 \mathrm{~m}^{2} / \mathrm{kw}\right)$, we calculate the solar panel generation capacity. 5) With multiplication by the output coefficient (0.7) and hourly solar radiation, we estimate the amount of PV among municipal areas and hours. In addition, we use July data as data of solar insolation. They show the most electricity generated annually in Japan.

\subsection{Method for estimation of residential electricity consumption}

Hasegawa and Inoue [6] reported that residential EC is affected strongly by the house type and household composition. Moreover, the NHK Broadcasting Culture Research Institute [8] reported that three factors strongly affect daily EC 
patterns. Those patterns can be designated as those of elderly people, single persons, and non-workers (retired persons). Based on the above, the estimation was carried in the following steps. 1) Calculate the amount of EC per household considering the difference. The difference is in the amount of EC by detached house and apartment building and the ratio according to house type. 2) We estimated the residential EC among whole municipalities, based on the calculation result from 1) and the electric bills by different size of household. 3) We set the pattern of daily EC per household. Additionally, we set the pattern of EC among municipalities. 4) Then we estimated the residential EC among whole municipalities and on an hourly basis. That was created by combining the amount of residential EC among municipalities with the pattern of EC among the municipalities.

\subsection{Method for estimating the amount of charge and chargeable time required for $\mathrm{EV}$}

This study is based on the premise that a society has EV in widespread use. Therefore, referring to Sekine et al. [9], we set a $28 \%$ adoption rate for EV of overall car ownership under three conditions such as the multiple car ownership households or not, mini-vehicle ownership or not, and travel distance per day of less than $30 \mathrm{~km}$ or not. Accordingly, we calculate the amount of charge and chargeable time necessary for EV. This calculation is based on the adoption rate and the daily manner of using EVs. Based on the above, the estimation is carried out in the following steps. 1) We calculate the amount of necessary charge (at a minimum) based on the distance travelled per day. 2) We extract the time zone of $\mathrm{EV}$ in the home and set the time zone as the electrifiable time. 3) When surplus electric power of the PV occurs in resident municipalities at the electrifiable time, it is assumed that surplus electric power is used for EV charging. 4) When EV can charge with more energy after satisfying a quantity of needed charge, it is assumed that the EV charges to the greatest extent possible to support domestic consumption of electricity at night. 5) In the case of a shortage of the amount of needed charge only by PV, then the amount of remaining needed of EV charge from an existing electric power supply in other time.

\subsection{Indication of local electricity production for local consumption}

This study defines the indication of the local electricity production for local consumption as the percentage to provide electrical power to residential EC by resident $\mathrm{PV}$ in own resident municipalities. When the degree of local electricity production for local consumption in municipality $i$ is $D L E_{i}$, then $D L E_{i}$ is expressed in eqn. (1), (2) and (3) as shown below.

$$
\begin{gathered}
\mathrm{DLE}_{\mathrm{i}}=\mathrm{LE}_{\mathrm{i}}+\mathrm{SE}_{\mathrm{i}} / \mathrm{REC}_{\mathrm{i}} \\
\mathrm{LE}_{\mathrm{i}}=\mathrm{EP}_{\mathrm{i}} / \mathrm{REC}_{\mathrm{i}} \\
\mathrm{SE}_{\mathrm{i}}=\mathrm{ES}_{\mathrm{i}}-\mathrm{NC}_{\mathrm{i}}
\end{gathered}
$$


$L_{\mathrm{i}}$ : Degree of local electricity production for local consumption before use of EVs; $\mathrm{SE}_{\mathrm{i}}$ : EV surplus electricity energy storage that can be used for residential electrical power; $\mathrm{REC}_{\mathrm{i}}$ : Total residential electricity consumption; $\mathrm{EP}_{\mathrm{i}}$ : Amount of electrical power to cover the residential consumption directly in PV; $\mathrm{ES}_{\mathrm{i}}$ : Total $\mathrm{EV}$ electricity energy storage from $\mathrm{PV} ; \mathrm{NC}_{\mathrm{i}}$ : Amount of necessary charge to travel for EV.

In addition, this study is based on the premise that a smart meter is installed in all households and that interactive flexibility of the electricity is enabled between households.

\section{Result}

\subsection{Relation between population size and the degree of local electricity production for local consumption}

Population size is basic data as a city characteristic. Figure 2 shows the relations between the degree of local electricity production for local consumption (DLE) and population size. According to the population size, municipalities across-thecountry are divisible into eight categories such as Tokyo's 23 wards, 20 ordinance-designated cities, and 6 with population size of less than 30,000 people to more than 500,000 people. DLE puts the average of each category's cities to use.

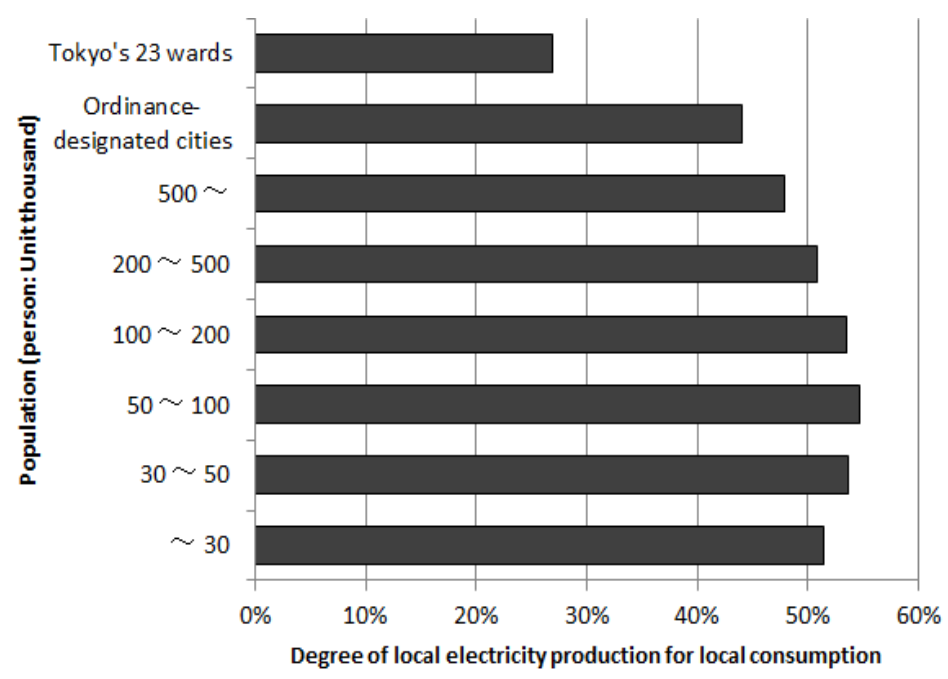

Figure 2: Average degree of the local electricity production for local consumption among population size.

1) The highest population category, rated at $55 \%$, is a city with more than 5,000 people and fewer than 100,000 . This rate is almost twice the category of Tokyo's 23 wards, which shows the lowest rate. 
2) This result is strongly related to the massive ratios of apartment buildings at Tokyo's 23 wards because the amount of PV per household, which is the basis of DLE, becomes less because of the large number of apartment buildings.

3) For municipalities of more than 50,000 people, as the population becomes less, DLE shows an increasing tendency. However, for a population size of fewer than 50,000 people, this trend shifts to a decline.

\subsection{Results of multiple regression analysis}

Next, we show details of the relation between DLE and city characteristics. We conducted a multiple regression analysis. The dependent variable is DLE calculated from traffic data among the municipalities satisfying reliability.

In regard to the city characters, Soltani et al. [10] shows that relationship between residential EC and city characters. However their study targeted only two cities and only 4 explanatory variables such as size of household. Therefore, this study considered the causal relationship about city characteristics of the scale, traffic, resident, housing, climate and region in order to cover the city characteristics data that may greatly affect the DLE. Accordingly we selected 11 explanatory variables from those characteristics.

The selected variables are presented in Table 1 . Parameters and $t$-values in Table 2 provide a clear representation of the relation between DLE and city character at Tokyo metropolitan area as follows:

Table 1: $\quad$ Definitions of respective values.

\begin{tabular}{|c|l|l|}
\hline Spell & \multicolumn{1}{|c|}{ Explanatory variable } & \multicolumn{1}{c|}{ Explanation } \\
\hline PD & Population Density & Population per hectare of the municipalities \\
\hline NS & Number of Stations & Number of stations among each municipalities \\
\hline MO & $\begin{array}{l}\text { Mini-vehicle Ownership } \\
\text { per household }\end{array}$ & $\begin{array}{l}\text { Number of personal vehicles divided by } \\
\text { household in the municipalities }\end{array}$ \\
\hline RA & Rate of Aging & $\begin{array}{l}\text { Ratio of people over 65 years to the population } \\
\text { of municipalities }\end{array}$ \\
\hline AH & $\begin{array}{l}\text { Average size of } \\
\text { Household }\end{array}$ & $\begin{array}{l}\text { City population divided by households in the } \\
\text { municipalities }\end{array}$ \\
\hline RM & Ratio of Multidwellings & $\begin{array}{l}\text { Multidwellings to total residential population in } \\
\text { the population }\end{array}$ \\
\hline RS & $\begin{array}{l}\text { Ratio of Satisfy the } \\
\text { quake-resistance standards }\end{array}$ & $\begin{array}{l}\text { Ratio of the household built after 1979 to the all } \\
\text { residential in the municipalities }\end{array}$ \\
\hline AS & Residential ratio of Daylight & $\begin{array}{l}\text { Ratio of the residence that daylight more than } 5 \\
\text { hours to all residences in the municipalities }\end{array}$ \\
\hline T’23 & Tokyount of Solar radiation 23 wards & Total insolation(MJ/m ${ }^{2}$ ) per day \\
\hline HD & Hokkaido & $\begin{array}{l}\text { Dummy variable: } 1 \text { for Tokyo's } 23 \text { wards, it is } \\
\text { 0 in other municipalities }\end{array}$ \\
\hline
\end{tabular}


842 The Sustainable City VIII, Vol. 2

Table 2: $\quad$ Results of multiple regression analysis.

\begin{tabular}{|c|c|c|c|c|c|c|c|}
\hline Spell & $\begin{array}{l}\text { Unstandardized } \\
\text { parameter }\end{array}$ & $\begin{array}{l}\text { Standardized } \\
\text { parameter }\end{array}$ & $t$-value & Spell & $\begin{array}{l}\text { Unstandardized } \\
\text { parameter }\end{array}$ & $\begin{array}{l}\text { Standardized } \\
\text { parameter }\end{array}$ & $t$-value \\
\hline PD & 0.000 & -0.172 & $-3.534 * *$ & $\mathrm{RS}$ & 0.561 & 0.580 & $17.888 * *$ \\
\hline NS & 0.000 & -0.080 & $-3.630 * *$ & $\mathrm{RD}$ & 0.266 & -0.280 & $9.652 * *$ \\
\hline MO & 0.093 & 0.209 & $5.015 * *$ & AS & 0.000 & 0.195 & $8.705 * *$ \\
\hline RA & -0.002 & -0.089 & $-2.320 *$ & T23 & -0.080 & -0.146 & $-4.632 * *$ \\
\hline $\mathrm{AH}$ & -0.080 & -0.286 & $-8.212 * *$ & HD & -0.058 & -0.116 & $5.032 * *$ \\
\hline RM & -0.221 & -0.446 & -8.458 & $\begin{array}{l}\text { Con- } \\
\text { stant }\end{array}$ & -0.204 & & $-2.656 * *$ \\
\hline
\end{tabular}

Adjusted $R^{2}: 0.730$

$* * p<0.1 * p<0.05$

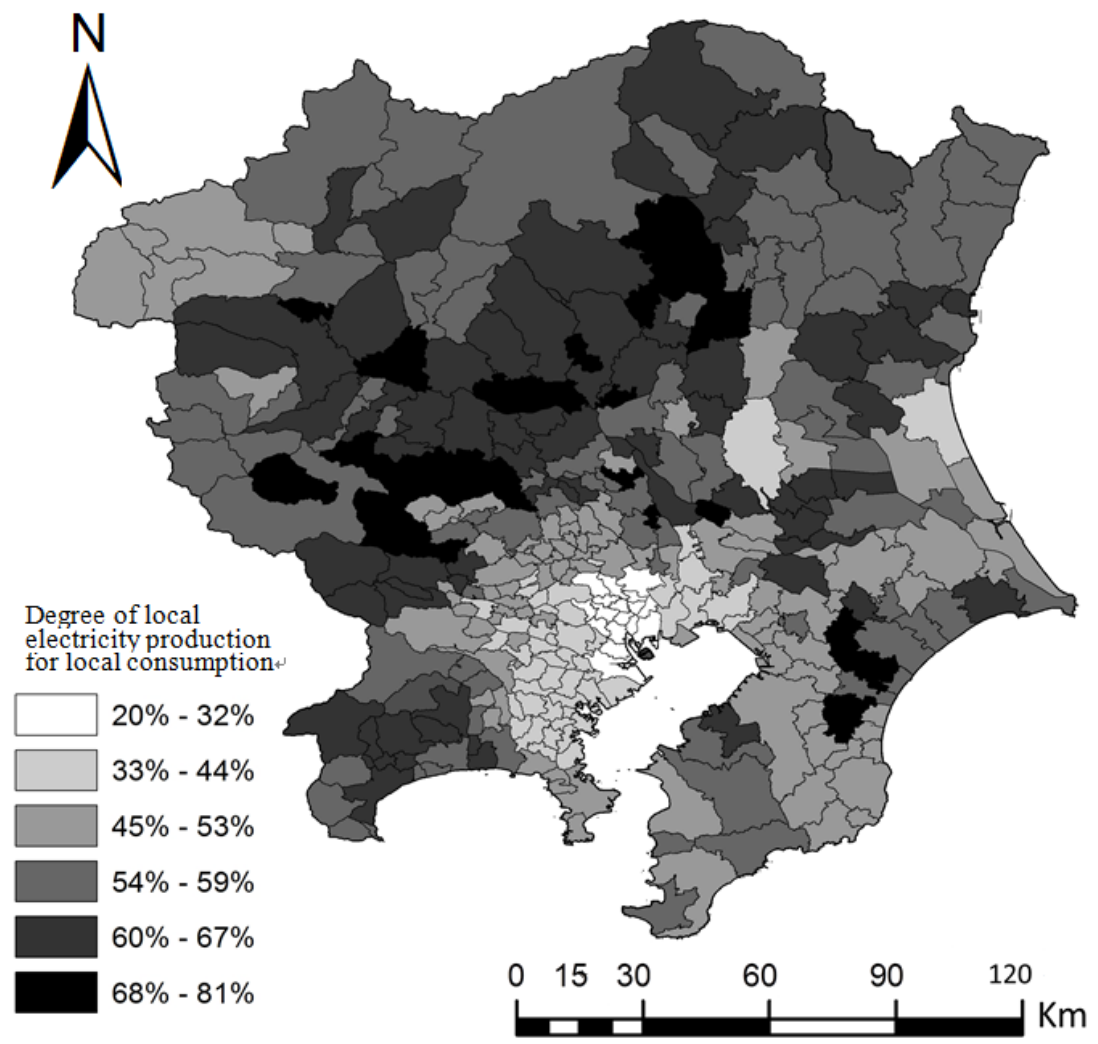

Figure 3: Map showing the degree of local electricity production for local consumption at the Tokyo metropolitan area. (Municipalities without reliability are estimated by multiple regression analysis.) 
1) The municipalities located in suburban areas, in which usually have low population density and fewer stations, show the trend to be a higher rate of DLE.

2) In addition, the municipalities showing high car ownership tend to increase DLE. Areas with a high rate of car ownership are thought to be multiple car ownership households. Therefore, future EV penetration in those areas is expected to be higher.

3) In fact, when discussing the effective introduction of a smart grid, it is important to consider the possibility of EVs' increased use for storage of surplus PV power.

4) With emphasis on residential character, municipalities with progressive nuclear families and depopulation tend to have a high rate of DLE. It is thought that the smaller the household, the lower the amount of residential EC.

5) Figure 3 depicts that DLE at Tokyo metropolitan area was calculated as $81 \%$ at the highest and $20 \%$ at the lowest. Consequently, these results indicate the effect of introducing smart grids as creation of large gaps among municipalities.

6) The effect is greater in suburban areas than in urban areas of metropolitan Tokyo. Although the distance from the urban area extends far into suburban areas, this effect decreases with distance, as shown spatially in Figure 3.

\section{Conclusion}

This study analyzed the relation between DLE by PV and city characteristics for introduction of smart grids in all municipalities in Japan. The analysis revealed that the effects of introducing smart grids differ greatly among municipalities: Selection of the priority of municipalities is of strategic significance for introduction of smart grids. Furthermore, this result is influenced by factors such as population size, ratio of detached houses and apartment buildings, and the manner of using electric vehicles, all of which are important for consideration of selecting municipalities. Moreover, it is revealed that suburban municipalities around inner city areas are suitable as cities for effective introduction of smart grid using PV. Therefore, these results indicate that discussion of introduction of smart grids considering the municipality characteristics is important in future analyses.

\section{References}

[1] Lund, H. and Kempton, W., Integration of renewable energy into the transport and electricity sectors through V2G, Energy Policy 36(9), pp. 3578-3587, 2008.

[2] Kang, J.E. and Recker, W. W., An activity-based assessment of the potential impacts of plug-in hybrid electric vehicles on energy and emissions using 1-day travel data, Transportation Research Part D, Vol. 14, Issue 8, pp. 541-556, 2009. 
[3] Brand, S. A., Dynamic pricing for residential electric customers: A ratepayer advocate's perspective, The Electricity Journal, Vol. 23, Issue 6, pp. 50-55, 2010.

[4] Alexander, B. R., Dynamic pricing? Not so fast! A residential consumer perspective, The Electricity Journal Vol. 23, Issue 6, July, pp. 39-49, 2010

[5] Yonezawa, K. and Matsuhashi, K., Estimation of Transport $\mathrm{CO}_{2}$ Emissions by Municipalities in 1999 and 2005, SESD Discussion Paper Series Technical Report, 2009, (in Japanese).

[6] Hasegawa, Y. and Inoue, T., Energy consumption in housing on the basis of national scale questionnaire: study of influence of residential characteristic and dispersion of energy consumption Part 1, Transactions of AIJ. Journal of Environmental Engineering (583), pp. 23-28, 2004, (in Japanese).

[7] Agency for Natural Resources and Energy, Research report: Basic research projects to promote the introduction of new energy 2011, (in Japanese).

[8] NHK Broadcasting Culture Research Institute, NHK national life time study: Life time of the Japanese. 2011, (in Japanese).

[9] Sekine, Y., Miyasaka, J., Ishida, H., Tsutsumi, M. and Okamoto, N., Estimation of potential demand for electric vehicles in multi-vehicle households, proceedings of infrastructure planning, Vol. 35, No. 135, 2006, (in Japanese).

[10] Soltani, A., Mehraein, M. and Sharifi, E., Urban features and energy consumption at local level, Journal of Urban and Environmental Engineering, Vol. 6, No. 2, pp. 43-47, 2012. 